\title{
New host and geographical records and morphological details for Echinuria skrjabiniensis (Nematoda, Acuariidae) from shorebirds in Argentina
}

\author{
Julia I. Diaz ${ }^{*}$, Guillermo Panisse', Graciela Escudero² and John M. Kinsella ${ }^{3}$ \\ ${ }^{1}$ Centro de Estudios Parasitológicos y de Vectores (CCT La Plata-CONICET-UNLP), Calle 2 No. 584, 1900, La Plata, \\ Buenos Aires Province, Argentina. ${ }^{2}$ Centro Nacional Patagónico, Bvard. Brown No. 3600, 9120 Puerto Madryn, \\ Chubut Province, Argentina. ${ }^{3}$ HelmWest Laboratory, 2108 Hilda Avenue, Missoula, MT 59801 USA
}

\begin{abstract}
The acuarioid nematode Echinuria skrjabiniensis Efimov in Skryabin, Sobolev et Ivashkin, 1965 was found in Calidris bairdii and C. fuscicollis (Aves, Scolopacidae) examined from several locations from Patagonia, Argentina. These constitute new host records as well as the first record of this parasite species in South America. Using both light and scanning electron microscopies, new morphological details are provided, including the description of the left spicule and the number and the arrangement of male caudal papillae. The taxonomic history of the species is summarized, corroborating its correct spelling and valid name.
\end{abstract}

\section{Keywords}

Nematoda, Acuariidae, Echinuria, shorebirds, Calidris bairdii, C. fuscicollis

\section{Introduction}

Species of Echinuria Soloviev, 1912 (Acuariidae) are cosmopolitan nematodes parasitizing the proventriculus and gizzard of birds, mainly of the order Anseriformes.

The genus is characterized by cephalic cordons which anastomose but are not recurrent and two pairs of longitudinal rows of cuticular spines, which extend from the cephalic end to varying lengths of the body. Yamaguti (1961) listed 20 species as belonging to this genus and Ali (1968) and Clark (1979) described 3 new species. However, Wong et al. (1986) transferred 5 of these species to other genera, and listed another 5 species as species inquirendae because of inadequate descriptions.

The species listed by Yamaguti (1961) as Echinuria skrjabinensis Efimov (with no date given) has an unusual history. The first mention of this binomen is in the "Keys to the Parasitic Nematodes" by Skrjabin et al. (1949), where it is listed as "E. skrjabinensis Efimov, 1937" from the pied avocet, Recurvirostra avosetta (Linnaeus, 1758), with no description, illustration, or even a locality for the record. Sultanov et al. (1960) described specimens which "did not differ from those described by A.P. Efimov" from the little stint, Calidris minuta Leisler, 1812; and the sanderling, Crocethia alba Pallas, 1854, from the Amu-Darya River basin in Central Asia. In the Osnovy Nematodologii, Vol. 14, Skrjabin et al. (1965) listed a new spelling and date, "E. skrjabiniensis Efimov, 1949", and gave a description and illustrations cited as "...from Efimov, published for the first time". Efimov's collection locality for $R$. avosetta was listed as "in the vicinity of the Aral Sea". Smogorzhevskaya (1990) described and illustrated specimens of E. skrjabiniensis from C. minuta from the Ukraine and also listed records from the dunlin, Calidris alpina Linnaeus, 1758, and the curlew sandpiper Calidris ferruginea (Pontoppidan, 1763).

Host records of E. skrjabiniensis from North America include Wilson's phalarope, Steganopus tricolor (Vieillot, 1819), from Colorado and Montana by Schmidt and Frantz (1972) and C. alpina from Alaska by Canaris and Kinsella (2007). There are no published records of this species from South America.

The aim of this paper is to provide new morphological details on E. skrjabiniensis based on specimens recovered from Baird's sandpiper, Calidris bairdii Coues, 1861, and the white- 
rumped sandpiper, Calidris fuscicollis (Vieillot, 1819), from Patagonia, Argentina, expanding its known geographical range and host distributions.

\section{Materials and methods}

A total of 44 Calidris bairdii and 48 C. fuscicollis (Aves, Scolopacidae) were collected in January, during their winter migration in Patagonia, Argentina, in the Austral summers of 1999 and 2004 to 2009 (excepting 2007). Birds were occasionally found dead, died of accidents during captures (Permits $\mathrm{N}^{\mathrm{o}} 19 / 04,02 / 05,10 / 6,02 / 08,48 / 08 \mathrm{DF}$ and FS Chubut), or were collected during other research projects (Permits $\mathrm{N}^{\circ}$ 406/05 DFS Santa Cruz Province, and $\mathrm{N}^{\circ}$ 92/05 DF and FS Chubut Province). Samples of hosts were examined from locations in both marine and freshwater environments.

The hosts were dissected in the field and viscera were fixed in $10 \%$ formalin. In the laboratory, nematodes were recovered from the proventriculus, preserved in $70 \%$ ethanol and studied in temporary mounts of $25 \%$ glycerine-alcohol using an Olympus BX5 $1{ }^{\circledR}$ microscope (LM). Measurements are given as the mean followed by the range in parentheses. They are in micrometers unless otherwise indicated. Several specimens were dried using the critical point method, examined by scanning electron microscopy (SEM) (Jeol 6360LV ${ }^{\circledR}$ ) and photographed. Voucher specimens were deposited in the Helminthological Collection of the Museo de La Plata, La Plata, Argentina (MLP).

The voucher specimens of E. skrjabiniensis of Schmidt and Frantz (1972) from S. tricolor and of Canaris and Kinsella (2007) from C. alpina were borrowed from the United States National Parasite Collection in Beltsville, Maryland, USA (Accession No. 71276 and 95298, respectively) as well as additional specimens from $S$. tricolor deposited by Schmidt and Frantz (1972) at the Harold W. Manter Laboratory of the University of Nebraska, Lincoln, Nebraska, USA (Nos. 33901 and 33902).

\section{Results}

\section{Echinuria skrjabiniensis Efimov in Skrjabin, Sobolev et Ivashkin, 1965 (Fig. 1A-I)}

Syn.: Echinuria skrjabinensis Efimov, 1937 sensu Skryabin, Shikhobalova et Sobolev, 1949; Echinuria skrjabinensis Efimov, 1949 sensu Sultanov, Ryzhikov et Kozlov, 1960; Echinuria skrjabiniensis Efimov, 1949 sensu Smogorzhevskaya, 1990.

Hosts: Calidris bairdii and C. fuscicollis.

Locality: Chubut Province: Estancia María Cristina (433' $\left.\mathrm{S}, 70^{\circ} 38^{\prime} \mathrm{W}\right)$, Sarmiento $\left(45^{\circ} 35^{\prime} \mathrm{S}, 6^{\circ} 07^{\prime} \mathrm{W}\right)$ and Estancia Quicahua $\left(42^{\circ} 27^{\prime} \mathrm{S}, 71^{\circ} 13^{\prime} \mathrm{W}\right)$ for $C$. bairdii, and Caleta Valdés $\left(42^{\circ} 30^{\prime} \mathrm{S}, 63^{\circ} 25^{\prime} \mathrm{W}\right)$, Bahía Bustamante $\left(54^{\circ} 06^{\prime} \mathrm{S}\right.$, $\left.66^{\circ} 31^{\prime} \mathrm{W}\right)$, and Laguna del Ornitólogo $\left(43^{\circ} 14^{\prime} \mathrm{S}, 65^{\circ} 14^{\prime} \mathrm{W}\right)$ for C. fuscicollis.

Site of infection: Proventriculus.

Prevalence and mean intensity: $9 \%$ and 2.75 , respectively in C. bairdii; $6.2 \%$ and 18 , respectively, in C. fuscicollis.

Specimens deposited: MLP (6346) from C. bairdii and MLP (6347) from C. fuscicollis.

Adults and juveniles of E. skrjabiniensis were found. A single $C$. fuscicollis was infected with 50 juvenile nematodes, whereas adults were not present in the host.

Description (Fig. 1A-I): Cuticle with fine transversal striations. Pseudolabia well developed with apices pointed and continuous with anterolateral walls of buccal capsule (Fig. 1A, B). Amphids at base of pseudolabia. One-sided ventral cuticular swelling well developed at the cephalic end on both male and female (Fig. 1A). Two pairs of cephalic papillae at short distance posterior to pseudolabia and laterally disposed to cordons (Fig. 1B). Cordons originating at dorso-ventral sides of oral opening and extending posteriorly, going to lateral-ventral side, and anastomosing at middle level of muscular oesophagus. Each cordon exhibiting transverse markings posteriorly festooned (Fig. 1B). Two rows of spines beginning dorsal to cordons, running to lateral sides posterior to cordons, diminishing in size and extending as far as middle of body in male and near or beyond vulva in female (Fig. 1C, D, E). Dorsolateral row of spines beginning anteriorly to ventro-lateral one. Simple and inconspicuous deirids, located between cordons and spines at short distance from the beginning of spines and before junction between buccal cavity and oesophagus junction. Buccal cavity lined with fine transverse striations. Oesophagus divided into short muscular portion and a longer glandular portion. Inconspicuous postdeirid observed at end of row of spines (Fig. 1E).

Male $(n=3)$ : Total body length (TBL) $3.18(3.04-3.30)$ $\mathrm{mm}$. Width at mid-body 148 (125-170). Cordons 250 (230 290) long, corresponding to less than $10 \%$ of TBL. Buccal cavity 95 (75-115) long; muscular oesophagus 265 (230300) long; glandular oesophagus 1112 (980-1290) long. Nerve ring and deirids at 123 (105-135) and 94 (72-114) from anterior end, respectively. Posterior region of body curved ventrally. Spicules dissimilar. Left spicule slender, 290 (285-300) long, consisting of cylindrical proximal portion and guttered distal part. Tip of left spicule split at end in two branches, right branch bifurcated (Fig. 1G, H). Tip of left spicule surrounded by cuticular cap (Fig. 1H). Right spicule wider and curved, 117 (100-130). Four pairs of precloacal pedunculated papillae disposed in two groups, first and second pairs, and third and fourth pairs very closed together (Fig. 1F). Six pairs of postcloacal papillae, first and second pedunculated pairs located just posterior to cloaca; third pedunculated pair located at short distance from previous two pairs. Three last pairs sessile, located in the middle ventral line. Fifth and sixth pairs located near of tip of tail (Fig. 1I), smaller than others. Phasmids situated just posteriorly to sixth pair of papillae (Fig. 1I). 

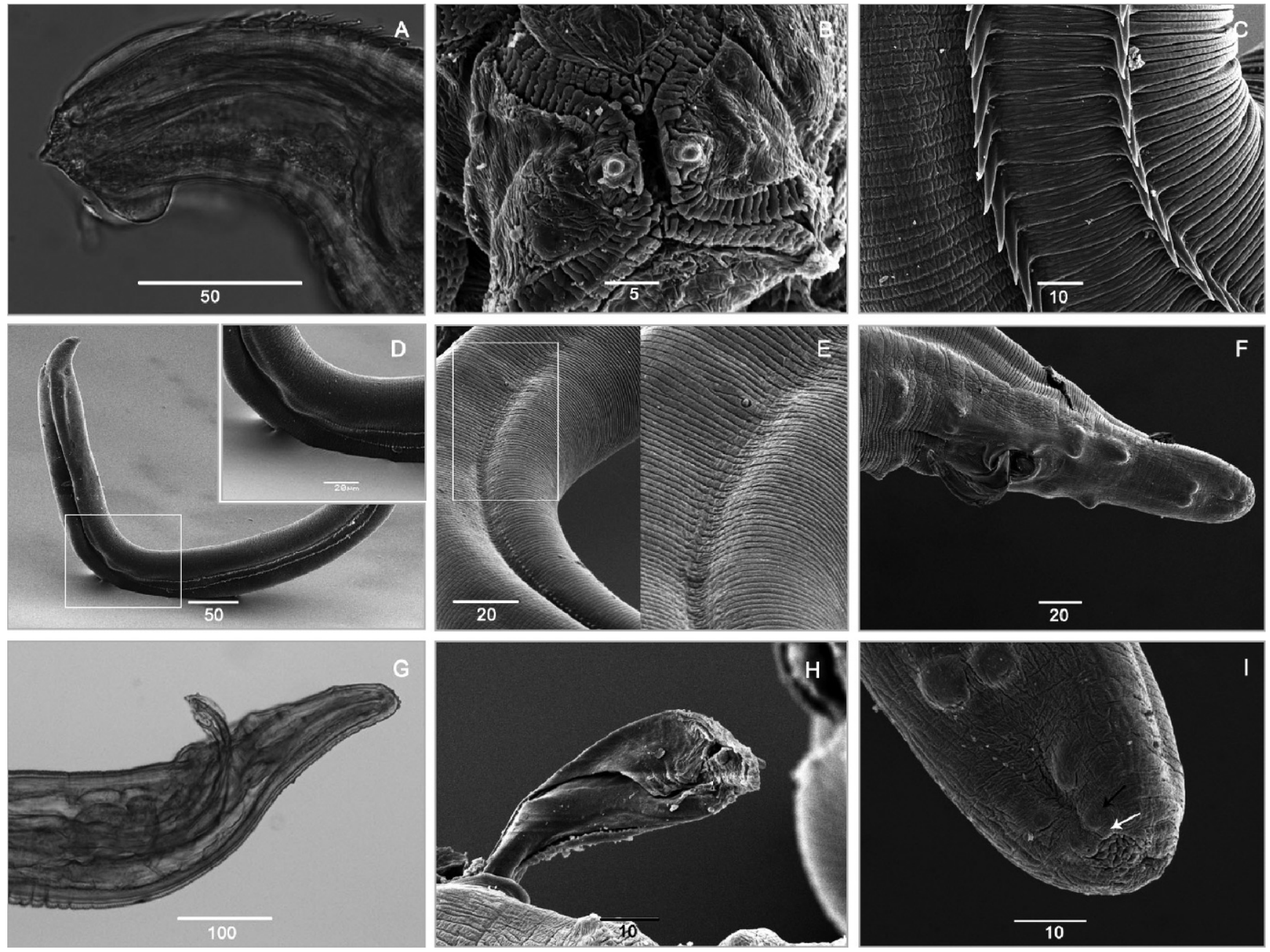

Fig. 1. Echinuria skrjabiniensis from Calidris bairdii and Calidris fuscicollis from Argentina. A. Anterior end (LM), lateral view, showing one-sided ventral cuticular swelling. B. Anterior end, apical view (SEM), showing pseudolabia, amphids, cephalic papillae and beginning of cordons. C. Detail of row of spines (SEM). D. Detail of ending of row of spines in a female near of posterior end (SEM). E. Postdeirid and end of the row of spines in a male (SEM). F. Posterior end of male at SEM, showing the arrangement of caudal papillae. G. Posterior end of male (LM), showing the arrangement of caudal papillae and left spicule. H. Tip of left spicule (SEM). I. Last pairs of postcloacal papillae (SEM), showing the fifth and the sixth pairs (black arrow) and the phasmids (white arrow). Scale bars in $\mu \mathrm{m}$

Female $(\mathrm{n}=5)$ : Total body length (TBL) $3.68(3.22-4.25)$ $\mathrm{mm}$. Width at vulva level $214(210-230)$. Cordons 395 (270$550)$ long, corresponding to $10.2 \%(7.3 \%-12.9 \%)$ of TBL. Buccal cavity 125 (110-145) long; muscular oesophagus 282 (260-300) long; glandular oesophagus 1239 (1035-1390) long. Nerve ring and deirids at 170 (150-210) and $111(100$ 118 ) from anterior end, respectively. Vulva in posterior region of body, at some distance from anus, 866 (720-1000) from posterior end, located commonly at 20-26\% of total length of body from posterior end. Vagina divided into vagina vera and vagina uterina. Eggs with formed larva, 32 (30-34) long by 20 (18-21). Tail short, conical, 92 (80-115), anus ventrally located (Fig. 1D).

The voucher specimens of E. skrjabiniensis from North America deposited by Schmidt and Frantz (1972) from S. tricolor and Canaris and Kinsella (2007) from C. alpina were consistent with our material in lengths of males and females, lengths of cordons, distribution of the cuticular spines, shape and size of the spicules (including the left spicule tip) and the position of the vulva relative to the posterior end.

\section{Discussion}

Since there seems to be no valid scientific publication according to the criteria of the International Code of Zoological Nomenclature by Efimov, either in 1937 (as cited by Skrjabin et al. 1949), or in 1949 (as cited by Skrjabin et al. 1965), the first valid description of Echinuria skrjabiniensis seems to be by Skrjabin et al. (1965), who give a description and illustrations "from Efimov published for the first time", and therefore, the correct name and spelling should be E. skrjabiniensis 
Efimov in Skrjabin, Sobolev et Ivashkin, 1965. The type host is Recurvirostra avosetta and the type locality is the vicinity of the Aral Sea. The specimens described by Sultanov et al. (1960), although assumed by those authors to be the same species as Efimov's specimens, were from different hosts (C. minuta and C. alba), so their description cannot with certainty be considered to have priority.

Of the 20 species of Echinuria listed by Yamaguti (1961), 4 [E. ciconiae (Gilbert, 1927); E. decorata Cram, 1927; E. hargilae Baylis et Daubney, 1923; E. leptoptili Gedoelst, 1916] were transferred to the genus Syncuaria, 1 [E. longevaginata (Molin, 1860)] was transferred to the genus Desportesius, and 5 [E. ardeae (Smith, Fox et White, 1908); E. calcarata (Molin, 1860); E. contorta (Molin, 1858); E. longeornata (Molin, 1860); E. sturni Ozerskaya, 1927] were regarded as species inquirendae by Wong et al. (1986). The description of another species, Echinuria nodulosa, mentioned by McDonald (1974) in a key to the genus, was never published; consequently this should be considered a nomen nudum. Echinuria borealis pamirica, described by Ryzhikov and Borgarenko in Skrjabin et al. (1965), was elevated to a full species, E. pamirica, by Smogorzhevskaya (1990), who listed Echinuria leiperi Ali, 1968 as its synonym. The 14 currently valid species of Echinuria seems to be: E. uncinata (Rudolphi, 1819) (type species); E. australis Clark, 1979; E. borealis Mawson, 1956 (with 2 subspecies); E. gilsoni Vuylsteke, 1953; E. heterobrachiata Wehr, 1937; E. hypognatha Wehr, 1937; E. minor Sandground, 1937; E. pamirica (Ryzhikov et Borgarenko, 1965 in Skrjabin, Sobolev et Ivashkin, 1965 (syn. E. leiperi); E. parva Cram, 1928; E. phoenicopteri (Seurat, 1916), E. querquedulae Johnston et Mawson, 1942, E. singhi Ali, 1968; E. skrjabiniana Lubimova, 1947; and E. skrjabiniensis. Of these 14, E. skrjabiniensis is the only species reported from hosts of the order Charadriiformes.

The shape of the left spicule (Fig. 1G, H) readily distinguishes males of E. skrjabiniensis from other species of the genus, many of which have a cleft left spicule tip, but none of which have an additional branch on one cleft. The left spicule is longer (285-300) than in E. gilsoni (260) and E. heterobrachiata (240-258) but considerably shorter than any of the other species (the males of E. querquedulae and E. phoenicopteri remain undescribed). Females of $E$. skrjabiniensis can be differentiated from other species using a combination of the following characters: body length less than $5 \mathrm{~mm}$; rows of cuticular spines symmetrical, beginning immediately posterior to pseudolabia; cordon length approximately $10 \%$ of body length; and vulva opening at 20 to $25 \%$ of body length from posterior end.

In the present specimens, left spicule was split at the end but surrounded by a cuticular cap. This feature was not present in the drawing of Smogorzhevskaya (1990); however, it was also observed in specimens from C. alpina from Alaska (Kinsella, unpublished data). Also we noted a ventral cuticular swelling at the cephalic end of males and females as it was observed by Smogorzhevskaya (1990). One difference observed between present specimens and the key provided by McDonald (1974) is the length of cordons. While the McDonald key lists cordon's length as over $15 \%$ of the total body length, in almost all present specimens they do not extend beyond the middle of the muscular oesophagus (i.e. $10 \%$ of total length).

These are the first records of E. skrjabiniensis from C. bairdii and C. fuscicollis as well as the first records in any host from South America. Baird's sandpiper breeds in high Arctic dry tundra, in northern Siberia, and from northern Alaska east to Baffin Island, Ellesmere Islands and northwest Greenland, and at higher altitudes in southern Alaska, while the white-rumped sandpiper breeds on islands in the Canadian Arctic and Alaska (Chandler 2009). Both species are rare but regular vagrants in western Europe and both migrate extremely long distances to winter in the southern cone of South America. The birds arrived to northern South America around early October and to their wintering areas (e.g. Patagonia and other parts of Argentina) around a month later. According to Anderson (2000), development from infective larva to adult in Echinuria takes around 30-50 days. If we found adults but also juveniles in birds from Patagonia collected in January, it is probable that these infections were acquired in South America during the fall migration, but future studies are needed to show whether the life cycle can also be completed on the wintering grounds.

Previous to this work, there was only one record of an acuariid nematode in Nearctic migratory shorebirds in southern South America, Skrjabinocerca canutus Diaz Cremonte, Navone et Laurenti, 2005 from Calidris canutus rufa from Uruguay (Diaz et al. 2005).

Acknowledgements. We would like to thank Monica Abril and her work team for providing us many of the hosts. We specially thank Dr. Vasyl Tkach for his help in the translation of Russian texts and to Patricia Sarmiento of the Servicio de Microscopía Electrónica de Barrido of the Museo de La Plata. Field work was conducted with permits from the Secretaría de Turismo y Áreas Protegidas. Funding was provided by Agencia Nacional de Promoción Científica y Tecnológica (PICT 525/PICT 309) and Universidad Nacional de La Plata (N 628).

\section{References}

Ali M.M. 1968. Studies on spiruroid parasites of Indian birds. Part II. A new genus and five new species of Acuariidae, together with a key to the genus Echinuria. Journal of Helminthology, 42, 221-242. DOI: 10.1017/S0022149X0001782X.

Anderson R.C. 2000. Nematode Parasites of Vertebrates. Their Development and Transmission. 2nd Edition. CAB International, Wallingford, Oxon, U.K., 650 pp.

Canaris A.G., Kinsella J.M. 2007. Helminth communities from three sympatric species of shorebirds (Charadrii) from four summer seasons at Bristol Bay, Alaska. Journal of Parasitology, 93, 485-490. DOI: 10.1645/GE-3550.1. 
Chandler R. 2009. Shorebirds of North America, Europe, and Asia: A photographic guide. Princeton University Press, Princeton and Oxford, 448 pp.

Clark W.C. 1979. Echinuria australis n. sp. and Echinuria uncinata (Nematoda: Spirurida), parasites of ducks in New Zealand. New Zealand Journal of Zoology, 6, 7-12.

Diaz J.I., Cremonte F., Navone G.T., Laurenti S. 2005. Adult and larvae of Skrjabinocerca canutus n. sp. (Nematoda: Acariidae) from Calidris canutus rufa (Aves: Scolopacidae) on the southern Southwest Atlantic coast of South America. Systematic Parasitology, 60, 113-123. DOI: 10.1007/s11230-004-13794.

McDonald M.E. 1974. Key to nematodes reported in waterfowl. Department of the Interior Bureau of Sport Fisheries and Wildlife Resource Publication. No. 122, Washington, D.C., 44 pp.

Schmidt G.D., Frantz D.W. 1972. Helminth parasites of Wilson's phalarope, Steganopus tricolor Vieillot, 1819, in Montana and Colorado. Proceedings of the Helminthological Society of Washington, 39, 269-270.

(Accepted May 06, 2011)
Skrjabin K.I., Shikhobalova N.P., Sobolev A.A. 1949. Key to Parasitic Nematodes. Vol. 1. Spirurata and Filariata. Izd. Akademii Nauk SSSR, Moscow-Leningrad, 519 pp. (In Russian).

Skrjabin K.I., Sobolev A.A., Ivashkin V.M. 1965. Spirurata of Animals and Man and The Diseases Caused by Them. Spirurata. Part 3. Acuarioidea. In: (Ed. K.I. Skrjabin) Osnovy Nematodologii, Vol. 14. Izd. Nauka, Moscow, 572 pp. (In Russian).

Smogorzhevskaya L.A. 1990. Nematodes. Part 3. Acuarioidea. In: (Ed. V.P. Sharpilo) Fauna Ukrainy. Vol. 32. Part 3. Naukova Dumka, Kiev, 188 pp. (In Russian).

Sultanov M.A., Ryzhikov K.M., Kozlov D.P. 1960. On the nematode fauna of wild birds from the mouth of the Amu-Darya. Uzbekskiy Biologicheskiy Zhurnal, 1, 58-63 (In Russian).

Wong P.L., Anderson R.C., Bartlett C.M. 1986. Revision of the genus Syncuaria Gilbert, 1927 (Nematoda: Acuarioidea). Canadian Journal of Zoology, 64, 1186-1196. DOI: 10/1139/CJZ-64-51186.

Yamaguti S. 1961. Systema Helminthum. Vol. 3. The nematodes of vertebrates. Interscience Publishers, New York, 1261 pp. 